\title{
REFLEXÕES POLÍTICAS DE DELIO CANTIMORI: O PROJETO DE ESTADO ITALIANO E A FORMAÇÃO CIVIL COMO PROBLEMAS DE INTERPRETAÇÃO HISTÓRICA (1924-1943)
}

\author{
Felipe Araujo Xavier * \\ Universidade Federal de Juiz de Fora - UFJF \\ felipearaujoxavier@yahoo.com.br
}

\begin{abstract}
RESUMO: Este artigo tem como objetivo apresentar as reflexões histórico-políticas de Delio Cantimori voltadas para a relação entre o Estado Italiano e a formação ético-moral do povo. Levando em consideração as mudanças ideológicas do intelectual italiano, primeiramente, busco apresentar sua interpretação do projeto de sociedade fascista como a verdadeira revolução civil italiana, para depois explorar a inflexão política, na qual Cantimori se distanciou do pensamento Idealista Atualista e do Partido Nacional Fascista e depositou sua crença política no projeto ético-político comunista no contexto em que se interessava pelo estudo dos reformadores políticos radicais, utopistas e jacobinos italianos que atuaram na fase inicial do Risorgimento.
\end{abstract}

PALAVRAS-CHAVE: Delio Cantimori - Risorgimento - Fascismo - Utopistas -Jacobinos italianos.

\section{POLITICAL REFLECTIONS OF DELIO CANTIMORI: THE ITALIAN STATE PROJECT AND THE CIVIL FORMATION AS PROBLEMS OF HISTORIC INTERPRETATION}

\begin{abstract}
This article aims to present the historical and political reflections of Delio Cantimori focused on the relationship between the Italian State and the ethical and moral formation of the people. Considering the ideological changes of the Italian intellectual, first, I seek to present his interpretation of fascist project of society as the true Italian civil revolution, to approach after the political inflection, which Cantimori distanced from the thought Actual idealism and the National Fascist Party, to put his political beliefs in the communist project in the context which he interested about the study of radical political reformers, utopians and Italian Jacobins who acted in the beginning of Risorgimento.
\end{abstract}

KEYWORDS: Delio Cantimori; Unification of Italy; Fascism; Utopists; Italians Jacobins.

\footnotetext{
* Doutor pelo Programa de Pós-Graduação em História da Universidade Federal de Juiz de Fora.
} 
O termo Risorgimento foi recorrentemente utilizado para se referir ao complexo contexto de transformações econômicas, sociais e políticas, permeado por movimentos culturais e literários, iniciado no final do Settecento e estendido pelo Ottocento, até a Unificação Italiana, em 1970.

Dentro da historiografia italiana, o Risorgimento permaneceu como uma problemática interpretativa ainda hoje aberta para um profícuo debate entre intelectuais e estudiosos da história italiana. Muitos trabalhos se debruçaram sobre a trajetória e o pensamento de personagens como Vittorio Emanuel, Conde Cavour, G. Garibaldi e G. Mazzini, Vincenzo Gioberti, representados frequentemente como heróis da Unificação do Estado italiano, e personalidades menos famosas como Carlo Pisacane, Vincenzio Russo, Filippo Buonarroti, Andrea Luigi Mazzini, Vincenzo Cuoco, reformadores políticos radicais tão amistosos aos olhos de Delio Cantimori.

Como tantos outros intelectuais nascidos na Itália das primeiras décadas do Novecento, Delio Cantimori foi um estudioso italiano que cresceu e conheceu uma realidade política e social confusa e permeada por grandes transformações, em um arco de tempo muito restrito, na qual muitos estudiosos se empenhavam nas lutas partidárias, nos movimentos sociais e na construção de uma releitura da história da Unificação Italiana.

Sendo educado em um ambiente familiar inflamado pelos discursos republicanos paternos, desde os primeiros lapsos de consciência, Delio Cantimori conviveu com a ação e a reflexão política de seu pai, Carlo Cantimori, militante e representante do Partido Republicano e destacado estudioso das ideias de Giuseppe Mazzini.

Sua formação republicana ainda foi reforçada pelo próprio ambiente político romagnolo de tradição tipicamente mazziniana, não obstante, permeado pelo idealismo crociano e, sobretudo, gentiliano. ${ }^{1}$

Após terminar o Ensino Médio Clássico, em 1924, Delio Cantimori entrou no curso História da Filosofia, na Facoltà di Lettere e Filosofia da Università di Pisa, e

1 CANTIMORI, Delio. Eretici italiani del Cinquecento e altri scritti. $2^{\circ}$ Ed. Torino: Guilio Einaudi editore, 1992. p. 11. 


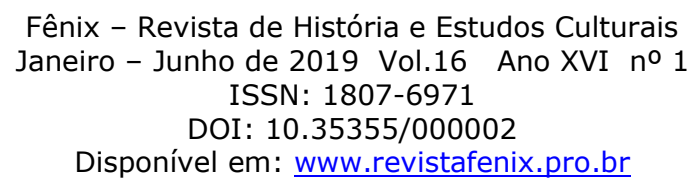

venceu o concurso para uma vaga na Scuola Normale Superiore di Pisa, instituições nas quais o pensamento idealista se tornou fortemente presente naqueles anos.

Nesse universitário pisano, o jovem estudante se relacionou com professores como o grande expoente do Idealismo Atualista e Ministro da Educação, entre 1922 e 1924, Giovanni Gentile, o qual, nesse período, lecionava História da Filosofia na Scuola Normale, e Giuseppe Saitta, professor titular da cátedra de filosofia na Università di Pisa.

Sob a influência da sua formação político-cultural romagnolo familiar e a aproximação pessoal com seus professores, Delio Cantimori passou a confiar na via fascista como forma de concretização de uma verdadeira Revolução republicana ${ }^{2}$ de cunho universalista empenhada na formação civil, ética e moral do povo italiano, em busca de eliminar a distância entre as massas e a elite intelectual, herdando os ensinamentos do Renascimento e do Risorgimento e superando-os.

Não obstante, na década de 1930, Delio Cantimori começara a se decepcionar com o posicionamento do governo fascista. Nesse período, o estudioso romagnolo colecionou experiências políticas essencialmente contrastantes ao seu posicionamento ideológico como, por exemplo, a Concordata, a crise do Estado Ético Corporativo, a Guerra da Etiópia, a aproximação de Mussolini aos preceitos políticos nacionalsocialistas com a instauração das leis raciais.

Essa lacuna espiritual deixada pela desilusão com o fascismo foi gradualmente preenchida pelos estudos marxistas e suas relações ilegais com integrantes do PCI, tendo destaque sua esposa, Emma Mezzomonti.

Após publicar seu livro Eretici italiani del Cinquecento ${ }^{3}$, em 1940, Cantimori foi nomeado professor da Scuola Normale Superiore di Pisa e três anos depois, seria impresso sua segunda obra Utopisti e Riformatori italiani. Ricerche storiche (17941847), ${ }^{4}$ no qual deixou a marca de seu interesse pelo posicionamento ético e moral e

2 CANTIMORI, Delio. Federico Chabod. Revista Belfagor, XV, 1960. In: CANTIMORI, Delio. Storici e storia. Metodo, caratteristiche e significato del lavoro storiografico. $1^{\circ}$ Ed. Torino: Giulio Einaudi editore, 1971. p. 285. Cf. PERTICI; Roberto. Mazzinianesimo, fascismo, comunismo: l'itinerario politico di Delio Cantimori (1919-1943). Milano: Editoriale Jaca Book SPA, 1997. p. 40-50. MICCOLI, Giovanni. Delio Cantimori. La ricerca di una nuova critica storiografica. Torino: Giulio Einaudi editore, 1970. p. 22.

3 CANTIMORI, Delio. Eretici italiani del Cinquecento. Ricerche storiche. Firenze: Sansoni, 1939.

4 CANTIMORI, Delio. Utopisti e Riformatori italiani. Ricerche storiche (1794-1847). Firenze: Sansoni, 1943. 


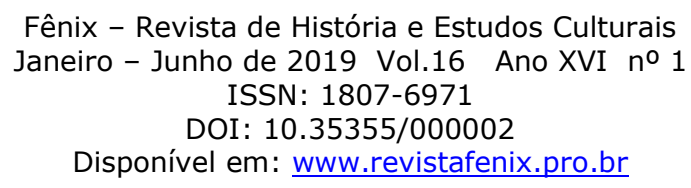

pela defesa da tolerância dos hereges italianos do Cinquecento que, segundo Cantimori, permaneceram vivos nos reformadores políticos radicais que deram os primeiros passos na luta pela Unificação Italiana.

Dessa maneira, faz-se necessário uma análise mais elaborada da leitura cantimoriana sobre o Risorgimento como evento histórico herdeiro do pensamento renascentista voltado para a formação ético-moral italiana, na qual se deve penetrar na relação entre a formação idealista de Delio Cantimori, sua simpatia pelo Estado Ético Corporativo fascista, a crise do paradigma idealista atualista e sua guinada para o comunismo, quando o estudioso romagnolo redigia seu principal trabalho específico sobre o Risorgimento italiano: Utopisti e Riformatori italiani (1794-1847).

\section{A SUPERAÇÃO DO RISORGIMENTO: OS FASCISMOS CANTIMORIANOS E A VERDADEIRA REVOLUÇÃO CIVIL ITALIANA.}

Perante a crise do liberalismo, o discurso fascista de atrelar a economia e os trabalhadores ao Estado através das corporações se reforçou e foi bem recebido por boa parte da intelectualidade italiana e, em específico, por Delio Cantimori.

O projeto fascista corporativo começou a representar, para muitos, a "terceira via”, uma nova fórmula político-econômica que sintetizou as características e superou as intempéries dos modelos produtivos socialista e capitalista. ${ }^{5}$

Fruto da sua Bildung cultural e política ligada à educação republicana mazziniana, agora organizada dentro dos preceitos teóricos atualistas gentilianos, em meados da década de 1920, o jovem Cantimori constituiu seu ideal de Fascismo como forma de religiosidade não confessional, que teria superado o catolicismo e traduzido, no universo político, a moral e a nova ética que deram base para a verdadeira revolução civil italiana.

Nesse âmbito de pensamento, o estudante romagnolo acreditava que o PNF seria a instituição capaz de promover a verdadeira revolução republicana e sindicalista

5 CHIANTERA-STUTTE, Patricia. Delio Cantimori: un intellettuale del novecento. Roma: Carocci, 2011. p. 20. 
de caráter europeu, integrando as massas ao Estado, através da ação intelectual e política dos representantes do governo no esforço de formação do cidadão italiano. ${ }^{6}$

Entretanto, a concepção de religiosidade laica da política de Estado fascista, formada por Cantimori, foi abalada no findar dos anos 20, quando Benito Mussolini promoveu a Concordata entre Estado e Igreja Católica e promulgou o Tratado de Latrão, reafirmando os valores católicos e arruinando - aos olhos de Cantimori - a sacralidade do regime fascista idealista atualista não confessional.

Para o jovem intelectual, esses episódios representavam a vitória dos nacionalistas reacionários católicos sobre o fascismo, que perdia o poder de se transformar na nova visão religiosa baseada nos valores humanistas modernos do Risorgimento, levando os projetos de construção da realidade social, defendidos por G. Gentile, à uma relativa marginalidade e decepcionando profundamente muitos dos seus discípulos, entre eles Cantimori. ${ }^{7}$

Desiludido com a tomada de posição do regime fascista, o estudante romagnolo viu como saída a aproximação das correntes heterodoxas inclinadas à defesa do Estado Ético Corporativo - que ganhava espaço nos debates intelectuais naquele contexto com sua natureza revolucionária antiburguesa ainda bem próxima às reflexões atualistas gentilianas. $^{8}$

Segundo Chabod, entre 1931 e 1935, o sistema corporativista chamou a atenção de grupos que enxergaram nele o caminho para retirá-los da opressão do regime autoritário instalado, já que o debate sobre este tema gozou de uma liberdade privilegiada nos meios universitários, abrindo-se até mesmo para uma tendência de leituras fascistas que se aproximaram da esquerda ao levantarem suas bandeiras contra o capitalismo. ${ }^{9}$

6 PERTICI; Roberto. Mazzinianesimo, fascismo, comunismo: l'itinerario politico di Delio Cantimori (1919-1943). Milano: Editoriale Jaca Book SPA, 1997. p 40-50. MICCOLI, Giovanni. Delio Cantimori. La ricerca di una nuova critica storiografica. Torino: Giulio Einaudi editore, 1970. p. 22.

7 PERTICI; Roberto. Mazzinianesimo, fascismo, comunismo: 1'itinerario politico di Delio Cantimori (1919-1943). Milano: Editoriale Jaca Book SPA, 1997. p. 40-50.

8 CHIANTERA-STUTTE, Patricia. Delio Cantimori: un intellettuale del novecento. Roma: Carocci, 2011. p 21.

9 CHABOD, Federico. História do Fascismo. Lisboa: Editora Arcádia Limitada, 1963.p. 122 e 123. 


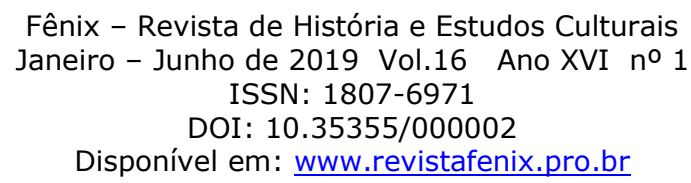

Naquele momento, um dos principais ideólogos do fascismo, o gentiliano Giuseppe Bottai, ${ }^{10}$ se tornou ministro das Corporações. Representante fascista romano, Bottai foi um dos principais redatores da Carta del Lavoro e também se destacou pela fundação da revista Critica Fascista, ${ }^{11}$ na qual saiu em defensa do Estado ético corporativo como valor moral e instrumento formador do cidadão subordinado à nação e consciente de sua participação na comunidade política.

Nesse contexto, o novo ministro renovou e fortaleceu o debate sobre o corporativismo na Itália, fundando, em 1930, o Arquivo de Estudos Corporativos e a Escola de Ciência Corporativa, os quais foram levados para Pisa. Ele também atuou na reforma do Conselho Nacional das Corporações. ${ }^{12}$

Mais especificamente, no campo da ciência econômica, em meio ao descrédito do modelo liberal, Delio Cantimori deparou-se com as ideias do filósofo Ugo Spirito, ${ }^{13}$ que, naquele contexto, se empenhava na tentativa de promover uma contestação do paradigma cientifico oficial, identificando, no modelo corporativo fascista, a base de renovação da ciência econômica, a qual, diante da crise da Europa, estava aberta para debates. ${ }^{14}$

Segundo Ostenc, entre esses dois pensadores gentilianos, o jovem estudante teve um interesse particular pelos escritos de Ugo Spirito e por sua proposta de “corporação proprietária", na qual defendeu a propriedade dos meios de produção às

10 Giuseppe Bottai defendia a concepção gentiliana de Risorgimento como revolução espiritual interrompida, vendo no fascismo a missão de cumprir esse movimento histórico. Foi um dos principais idealizadores do Corporativismo, não somente como instrumento para harmonizar as classes sociais, mas como organização totalitária capaz de atingir uma nova fase de vida social, se sobrepondo aos preceitos capitalistas até anulá-los. Assim, o corporativismo se posicionava como a "terceira via" que deveria superar tanto o liberalismo como o comunismo. DI NUCCI, Loreto. In: Dizionario del Fascismo. Torino: Giulio Einaudi editore, 2002. p. 194-197.

11 Critica Fascista foi um periódico criado por Bottai com o objetivo de criar uma nova classe política inspirada no fascismo, principalmente daqueles que viriam se amadurecendo dentro do regime implantado. Nela seus escritores debateram quatro temas principais: a natureza do PNF, o sistema corporativo, a relação entre fascismo e arte e a formação dos jovens. Ver: DE GRAND, Alexander J. Dizionario del Fascismo. Torino: Giulio Einaudi editore, 2002. p. 373 e 374.

12 PERTICI; Roberto. Mazzinianesimo, fascismo, comunismo: l'itinerario politico di Delio Cantimori (1919-1943). Milano: Editoriale Jaca Book SPA, 1997. p. 56.

13 Ugo Spirito foi formado em ambiente positivista, até que se tornou discípulo de G. Gentile, em 1918, e se aproximou, em 1924, a Bottai colaborando na Critica Fascista. PARLATO, Giuseppe. Dizionario del Fascismo. Torino: Giulio Einaudi editore, 2002. p. 660.

14 PERTICI; Roberto. Mazzinianesimo, fascismo, comunismo: 1'itinerario politico di Delio Cantimori (1919-1943). Milano: Editoriale Jaca Book SPA, 1997. p. 56. 


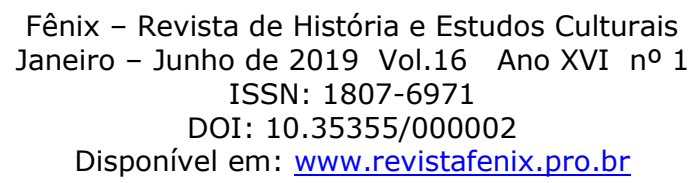

corporações para fundir capital e trabalho e realizar uma completa identificação entre individuo e Estado.

Mesmo sendo alvo de críticas dos fascistas, nacionalistas, industriais e conservadores, que o acusaram de bolchevismo, e da esquerda, que o classificou como utópico, Spirito foi considerado por Cantimori o último defensor do corporativismo, e sua tese, a mais coerente entre as visões voltadas para a temática. ${ }^{15}$

Portanto, agora próximo do ideal de Estado Ético Corporativo e sensível ao fortalecimento de novos atores políticos que vinham ganhando voz dentro do regime fascista, Delio Cantimori se levantou contra as correntes reacionárias próximas às interpretações neoguelfas e contrárias à revolução anticlerical do Risorgimento, que se declaravam aderentes ao fascismo.

Como ponto de partida, o jovem intelectual veio a reforçar o perfil inovador do fascismo como movimento de ação e não de reação, como queriam os reacionários. Por isso, segundo Cantimori, o comportamento desses reacionários em se declararem revolucionários se apresentava como um subterfúgio para se inserirem no regime e conservarem-se no poder. ${ }^{16}$

é claro que eles assumem a veste revolucionária por pura demagogia, ou, se querem, por razão didática ou propagandista, bem conscientes do seu verdadeiro caráter e das suas verdadeiras intenções. Se nós nos aproximarmos um pouco, descobrimos que os seus propósitos vão da repressão pura e simples daquilo que os verdadeiros revolucionários conquistaram fatigosamente à restauração, da monarquia absoluta dos lírios de ouro ou da tradição do Sacro Romano Império de Nação alemã ou da Europa católica daqueles belos tempos sonhados por Novalis, e assim por diante. ${ }^{17}$

15 PARLATO, Giuseppe. Dizionario del Fascismo. Torino: Giulio Einaudi editore, 2002. p. 660. Ostenc ressaltou a incerteza sobre a adesão do jovem italiano à proposta de corporação proprietária, porém assegurou que Cantimori concordava com sua crítica à ciência econômica alicerçada ao abstrato formalismo, individualismo, liberalismo e à clássica teoria do homo economicus. Dessa maneira, o anticapitalismo cantimoriano encontrou no pensamento de Spirito um paradigma que combatia o modelo científico baseado nos preceitos liberais. Entretanto, segundo Ostenc, apesar do interesse de Cantimori sobre o assunto, a problemática corporativa nunca construiu uma teoria pautada em reflexões analíticas significativamente concretas, não participando pessoalmente dos principais debates ocorridos na década de 30, a qual o próprio estudioso italiano afirmou ser o grande momento do corporativismo. OSTENC, Michel. Cantimori e l'idealismo gentiliano. p. 19-29. In: PERFETTI, Francesco; DI RIENZO, Eugenio. (org.). Delio Cantimori e la cultura politica del novecento. Firenze: Casa editrice Le Lettera, 2009. p 26 e 27.

16 CANTIMORI. Delio. Fascismo, nazionalismi e reazioni. Vita Nova, VII, 1931. P 3-6. In: Politica e storia contemporanea. Torino: Einaudi, 1991.p. 82 e 83.

17 Ibid., p. 83. 
Dessa maneira, Cantimori acreditava que o Estado Corporativo e a Revolução fascista seriam os atores históricos capazes de eliminar os ideais e as atitudes conservadoras tendenciosas e de implantar uma nova era na história política italiana e europeia. Seriam os arautos de uma verdadeira solução para o problema do Estado Moderno, o qual não fora superado antes, nem mesmo pelo desenrolar da Revolução Francesa. $^{18}$

O intelectual italiano ainda fez alvo as interpretações dos "concordatários" sobre a revolução fascista, que teriam como base a negação dos ideais políticos do Risorgimento italiano, o que, no entender de Cantimori, soaria como um desaforo para o processo de desenvolvimento do verdadeiro fascismo baseado no cumprimento dos preceitos políticos mazzinianos. ${ }^{19}$

Revolução e revolução do povo - disse e repetiu a tempo o Duce - e não de pseudoaristocratas ou de cavaleiros de capa e espada. Revolução, isto é ação profundamente marcada no presente, viva de todas as exigências do momento atual, e não lembrança dos resíduos de um passado longínquo.

E revolução moderna, revolução do povo, revolução verdadeira significa revolução de caráter europeu e universal. Também aqui retorna de forma perigosíssima o equívoco que queria fazer do Fascismo uma reação e queria renegar o Risorgimento italiano, que foi verdadeira e profundamente europeu. ${ }^{20}$

Segundo Cantimori, diferentemente do projeto fascista universalista de cunho mazziniano, os reacionários pensavam em uma futura Europa unida, mas como uma espécie de renovação da Santa Aliança. Entretanto, para o estudioso italiano, o Duce não era um general reacionário, mas, sim, o líder responsável por realizar a Revolução nacional iniciada com o Risorgimento, o qual teve como adversários históricos exatamente a Santa Aliança e a Restauração. ${ }^{21}$

18 CANTIMORI. Delio. Fascismo, nazionalismi e reazioni. Vita Nova, VII, 1931. P 3-6. In: Politica e storia contemporanea. Torino: Einaudi, 1991.p. 83 e 85.

19 CANTIMORI. Delio. Fascismo, rivoluzione e non reazione europea. Vita Nova, VII, 1931. P 759763. In: . Politica e storia contemporanea. Torino: Einaudi, 1991. p. 112-114.

20 Ibid., p. 115.

21 Ibid., p. 116. 
Os preceitos universalistas do Risorgimento italiano, em especial, as ideias mazzinianas de revolução republicana europeia, também impulsionaram Cantimori a uma concepção europeísta de fascismo.

Como V. Gioberti e Mazzini, o intelectual entendia a nação, a cultura nacional e a história universal em uma relação de interdependência. Na trama entre a história universal e a história nacional, o jovem buscou identificar o contributo específico italiano à história europeia, segundo o qual as nações e os estados não são átomos que poderiam viver isolados, desinteressando-se uns dos outros. ${ }^{22}$

Dessa maneira, Cantimori não tardou a entrar num debate sobre a relação entre Itália, Europa contemporânea e Sociedade das Nações, com a revista conservadora alemã - sua principal referência em relação aos acontecimentos políticos alemães Europäeische Revue, dirigida pelo príncipe Rohan. ${ }^{23}$

Em seus escritos, o jovem estudioso romagnolo apresentou sua insatisfação com o pensamento de centralização das lideranças europeias em três potências, Alemanha, França e Inglaterra, defendendo a necessidade fundamental da abertura de espaço para a Itália nos debates sobre a crítica situação do continente. ${ }^{24}$

O intelectual reforçava a importância da inserção da Itália nas questões continentais, pela sua histórica liderança política nas três unificações do continente - a primeira com Roma, a segunda com o Papado e a terceira com a cultura do Renascimento $^{25}$ - e pela a atual condição exemplar na qual o fascismo se encontrava em meio aos problemas socioeconômicos europeus, já que, em sua visão, “(...) aquilo que a Itália realiza não é só experimento, mas também ensinamento para as outras Nações". ${ }^{26}$

22 CANTIMORI. Delio. Questioni del giorno: L'Italia e l'Europa. Vita Nova, V, 1929. P 343-344. In: . Politica e storia contemporanea. Torino: Einaudi, 1991. p. 59 e 60. Cf. CHIANTERASTUTTE, Patricia. Delio Cantimori: un intellettuale del novecento. Roma: Carocci, 2011. p. 23.

23 O intelectual alemão Prinz von Rohan enxergava o Fascismo como um movimento político que combinou aspectos revolucionários e conservadores: a aspiração de uma nova ordem mundial mesclada à retomada dos valores tradicionais da nação. Cf. D'ELIA, Nicola. Delio Cantimori e la cultura politica tedesca (1927-1940). Roma: Istituto Storico Germanico di Roma \& Viella, 2007. p. 40 .

24 CANTIMORI, Delio. Questioni del giorno: Osservazioni sulla Società delle Nazioni. Vita Nova, IV, 1928, p. 970-971. In: Politica e storia contemporanea. Torino: Einaudi, 1991. p. 55.

25 CANTIMORI, Delio. Stati Uniti d'Europa. Vita Nova, V, 1929, p. 819-22. In: Politica e storia contemporanea. Torino: Einaudi, 1991. p. 65.

26 CANTIMORI, Delio. Questioni del giorno: L'Italia e l'Europa. Vita Nova, IV, 1928, p. 970-971. In: . Politica e storia contemporanea. Torino: Einaudi, 1991. p. 59. 
Seguindo esta linha de pensamento, Delio Cantimori ressaltou a importância de entender o fascismo e seu pensamento filosófico dando-lhe o status de cume de um processo histórico de porte ocidental, a "terceira via" que encontrou o caminho para a restauração da harmonia continental através do equilíbrio dos Estados e dos ideais criados por aquela civilização, superando o projeto liberal democrático e o comunista. ${ }^{27}$

Dentro dessas discussões europeístas, Delio Cantimori também despontou como um dos intelectuais italianos mais atentos às mudanças do universo político alemão, escrevendo um grupo de textos, no periódico Vita Nova, que se direcionava para o complexo movimento neoconservador alemão. Colaborando para a revista Leonardo, o intelectual romagnolo sinalizava para os seus primeiros contatos mais aprofundados com o marxismo.

Não obstante, aqueles anos de 1930 foram marcados por experiências importantes tanto para a vida política e cultural europeia como um todo, quanto para a carreira de Cantimori.

O intelectual italiano assistiu ao colapso do Estado Corporativo Ético Fascista acompanhado pela crise do idealismo atualista, ao mesmo tempo em que abandonava a filosofia para se adentrar nos estudos filológicos da ciência História, desenhando uma nova interpretação da formação da Europa Moderna e da realidade política que vivenciava. Agora, Cantimori saia em defesa não somente da tolerância como também da formação de um Estado como instituição laica provedora da racionalidade, em contraposição aos instintos inflamados pelo irracionalismo e pela intolerância política e racial de então, presentes tanto no fascismo quanto no nacional-socialismo.

\section{GIACOBINI, UTOPISTI E RIFORMATORI ITALIANI: ESTUDOS SOBRE O RISORGIMENTO E O COMUNISMO COMO REVOLUÇÃO ÉTICO-MORAL ITALIANA.}

Os estudos de Delio Cantimori sobre os reformadores, utopistas e jacobinos italianos do final do Settecento e da primeira metade do Ottocento foram permeados por uma longa trajetória politicamente conturbada, que retoma o ano letivo de 1932 e 1933,

27 PERTICI; Roberto. Mazzinianesimo, fascismo, comunismo: l'itinerario politico di Delio Cantimori (1919-1943). Milano: Editoriale Jaca Book SPA, 1997. p. 37-61. 
quando ainda lecionava no Ensino Médio, em Pavia, e passa por todo o processo de inflexão do fascismo ao comunismo.

Em Pavia, o então jovem professor do Liceo Classico Ugo Foscolo teve a oportunidade de fazer amizade com dois estudiosos e expoentes da escola histórica positiva: Baldo Peroni, que dava aulas na mesma escola que Cantimori, e Renato Sòriga, que era diretor do Museo Civico di Pavia. ${ }^{28}$

Ambos os estudiosos foram responsáveis por uma verdadeira lição de método de estudo e indicações sobre o período inicial do Risorgimento, em meio às polêmicas suscitadas pela tese do professor universitário Ettore Rota ${ }^{29}$, época em que o Settecento italiano foi interpretado, ideologicamente, a partir do nacionalismo que permeava o ambiente fascista italiano daqueles tempos. ${ }^{30}$

No necrológio dedicado a Peroni, Cantimori afirmou que o colega tinha dado uma resposta aos estudos nacionalistas que negavam a importância da relação entre a Revolução Francesa, as conquistas de Napoleão e a história italiana do Risorgimento, a partir de suas pesquisas sobre a ação dos patriotas italianos que portaram e aplicaram os ideais revolucionários franceses na formação da Republica Cisalpina. ${ }^{31}$

Renato Sòriga, estudioso da carbonária, da maçonaria e de outras sociedades secretas e movimentos conspiratórios do Settecento e início do Ottocento - interessado pela evolução do pensamento e da ação dos primeiros patriotas italianos e pela formação da consciência nacional entre 1789 e 1831 - permitiu que Cantimori tivesse contato com materiais editados e inéditos, que se encontravam nos arquivos e na biblioteca do museu em que trabalhava, sobre a história da Cisalpina, da maçonaria e, sobretudo, de Filippo Buonarroti ${ }^{32}$ (1761-1837). ${ }^{33}$

28 MICCOLI, Giovanni. Delio Cantimori. La ricerca di una nuova critica storiografica. Torino: Giulio Einaudi editore, 1970. p. 99.

29 Ettore Rota foi professor de história moderna na Università di Pavia. Dedicou-se aos estudos do Settecento, em busca de apresentar as origens e os motivos autóctones do Risorgimento.

30 AGUZZI. Luciano. Utopisti e Riformatori sociali nell'opera di Delio Cantimori (1937-1943). p. 558. In: Trimestre, 1989. p. 26 e 28.

31 Ibid., p. 28. Ver também: CANTIMORI, Delio. Baldo Peroni, necrologio. In: Rivista storica italiana. 1959. p. 520-523. A República Cisalpina (1797-1802) foi fundada após a invasão dos exércitos franceses com capital em Milão. Ela abrangeu a Lombardia, Emilia-Romagna e partes da Toscana e Veneto.

32 Filippo Buonarroti (1761-1837) foi um revolucionário italiano que carregava o ideal igualitário comunista. Depois da Revolução Francesa, exilou-se voluntariamente na ilha de Córsega. Logo se 


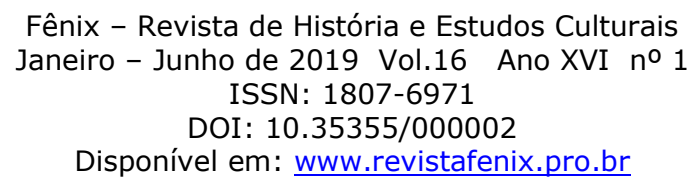

A partir desses contatos e impulsionado pelo prazer pelos estudos subterrâneos secretos dos hereges, Cantimori começava a reexaminar uma tradição reformadora radical revolucionária impulsionada pelos ideais da Revolução Francesa, que os setores conservadores e moderados combateram e, paulatinamente, foram sendo esquecidos pela historiografia italiana. ${ }^{34}$

Dessa maneira, o intelectual romagnolo montava as primeiras peças para a construção de um novo filão historiográfico que ligava os hereges italianos do Cinquecento aos reformadores, jacobinos e utopistas que antecederam ao Risorgimento italiano.

Aos olhos de Cantimori, esses políticos rebeldes portaram a consciência religiosa laica moderna herética, permeada pela tolerância e pelo radicalismo anabatista igualitário, o que os faziam donos de um novo projeto de sociedade italiana com mentalidade e valores morais renovados.

Naquele contexto de completa desilusão com o caminho tomado pelo fascismo, Cantimori desenhava, através de seus estudos sobre o igualitarismo de Gracco Babeuf ${ }^{35}$ até 1848, o seu comportamento crítico em relação ao Regime de Mussolini e transparecia, aos mais atentos, sua afeição, cada vez maior, pelos preceitos políticos comunistas e seu empenho no fortalecimento da historiografia marxista como via de superação aos ideais de sociedade fascista que se queria implantar. ${ }^{36}$

mudou para a França, onde teve contatos com Gracco Babeuf e os jacobinos, sendo deportado após a participação na Conjuração dos iguais.

33 AGUZZI. Luciano. Utopisti e Riformatori sociali nell'opera di Delio Cantimori (1937-1943). p. 558. In: Trimestre, 1989. p. 29.

${ }^{34}$ MICCOLI, Giovanni. Delio Cantimori. La ricerca di una nuova critica storiografica. Torino: Giulio Einaudi editore, 1970. p. 183.

35 François Noel Babeuf (conhecido como Gracco Babeuf, ao ser comparado aos irmãos Gracco Tribunos da Plebe, no período da República Romana) foi um jornalista e revolucionário francês jacobino, fundador da Conjuração dos iguais, movimento igualitário que propunha a comunidade dos bens de trabalho. Esse movimento, reprimido pelo Diretório, condenou todos seus integrantes à pena de morte.

36 AGUZZI. Luciano. Utopisti e Riformatori sociali nell'opera di Delio Cantimori (1937-1943). P. 558. In: Rivista Trimestre, s.d. 1989. p. 7 e 8. Andrea Luigi Mazzini (1814-1849) foi um político que viveu na França e colaborou com a Gazzetta Italiana, em Paris. Foi um defensor da esquerda hegeliana, tentando aplicar suas ideias à situação italiana. 
Dentro desse projeto, em 1936, Cantimori viajou a Leipzig e Dresden, para pesquisas ulteriores sobre os hereges, aproveitando a oportunidade para recolher documentos sobre a história e atividade de Andrea Luigi Mazzini. ${ }^{37}$

Em 1937, o estudioso publicou os primeiros artigos propriamente sobre o assunto, tendo como abertura uma pequena nota informativa sobre Gioacchino Trioli (1735-1799), na Enciclopedia italiana, na qual apresentou a trajetória do franciscano e escritor político, que, perante a chegada austríaca, suicidou-se, pelo temor de renegar as ideias da Revolução Francesa, que havia recebido com tanta admiração. ${ }^{38}$

Seu segundo texto sobre a nova temática foi um artigo intitulado Utopia, mais longo e bem mais significativo para o percurso de Cantimori - no qual o intelectual fez uma análise sobre o livro Die politische Insel. Eine Geschichte der Utopien von Platon bis zu Gegenwart, de H. Freyer, que representou as utopias como um comportamento particular do pensamento filosófico político, dotado de características constantes. Sua história não seria composta somente daquilo que os homens sonharam, mas, também, da fé na liberdade de dar forma a sua vida social, segundo valores e ideias.

Prosseguindo esse pensamento, Cantimori seguiu afirmando que, mais que como uma forma filosófica e teórica dotada de "leis", a utopia deveria ser tratada de maneira prática, "mesmo se enredada no racionalismo e no intelectualismo", e seu caráter "não é um jogo do arbítrio, mas uma projeção da vontade, que tem, então, a questão prática, teórica e imaginativa ao mesmo tempo".

$\mathrm{Na}$ opinião de Cantimori, não se pode nem mesmo falar de uma forma particular de pensamento filosófico e político, como queria H. Freyer, porque as utopias seriam as responsáveis por apontar os ideais ético-políticos, colocando como fins uma ação política, sem, nem mesmo, exigir realizações institucionais. ${ }^{39}$

Como enfatizou Luciano Aguzzi, Cantimori sempre definia as utopias como o caráter prático de uma projeção da vontade, um elemento programático que tende a agir

37 MICCOLI, Giovanni. Delio Cantimori. La ricerca di una nuova critica storiografica. Torino: Giulio Einaudi editore, 1970. p. 103. nota 2. AGUZZI, Luciano. Utopisti e Riformatori sociali nell'opera di Delio Cantimori (1937-1943). P. 5-58. In: Rivista Trimestre, s.d. 1989. p. 30.

38 AGUZZI, Luciano. Utopisti e Riformatori sociali nell'opera di Delio Cantimori (1937-1943). P. 558. In: Rivista Trimestre, s.d. 1989. p. 33.

39 CANTIMORI. Delio. Note e notizie: Le utopie. Giornale Critico della Filosofia Italiana, XVII, 1937. p 303-4. In: . Politica e storia contemporanea. Torino: Einaudi, 1991. p. 361 e 362. 


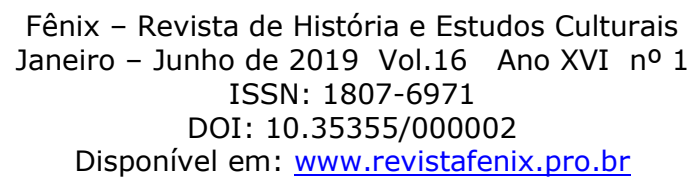

sobre a realidade, para modificá-la. Sejam as utopias religiosas, ou as políticas, ou sociais, todas nasceriam de uma situação conflituosa, exprimindo um desejo reformador que atinge o radicalismo extremo.

Para compreendê-las, não se pode resolvê-las em esquemas filosóficos, abstraindo-as de seus elementos teóricos. Temos que retomar os seus contextos históricos, o exame das forças sociais, dos homens e das ideias que entram em ação. Não obstante, a utopia seria, também, a expressão de uma imaturidade de situação histórica que consiste na contradição entre a sua modernidade e o anacronismo dos meios à disposição para realizá-las. ${ }^{40}$

Seguindo a trajetória da nova veia de estudos, dois anos depois, Cantimori publicou uma resenha sobre a antologia de escritos político-doutrinais de Vincenzo Cuoco (1770-1823), organizado por G. Tarroni, que teria como questão central o conceito de povo apresentado pelo reformador e escritor italiano.

Segundo o intelectual romagnolo, Tarroni afirmou que, para V. Cuoco, a única maneira de superar as experiências jacobinas seria através do reconhecimento da espontaneidade da vida popular, na qual o povo não é apenas, teoricamente, o detentor da soberania, mas, sim, o "criador de todas as formas da vida histórica e único sujeito da ação política". 41

Delio Cantimori ainda ressaltou sua dúvida em relação à possibilidade do organizador da coleção ter enxergado em V. Cuoco a resposta do problema conceitual de povo, em um contexto em que tal categoria ainda não era clara e normalmente associada às massas, ao terceiro estado, etc. A partir disso, o intelectual enfatizou a necessidade de um exame linguístico e histórico sobre o uso dessas palavras e a história do conceito. $^{42}$

40 AGUZZI, Luciano. Utopisti e Riformatori sociali nell'opera di Delio Cantimori (1937-1943). P. 558. In: Rivista Trimestre, s.d. 1989. p. 35.

41 CANTIMORI. Delio. Recensione di Vincenzo Cuoco. Il pensiero politico. A cura di G. Tarroni. Istituto Nazionale Fascista di Cultura. Cappelli, Bologna s.d. 1936. Leonardo, X, 1939. p. 17-19. In: Politica e storia contemporanea. Torino: Einaudi, 1991. p. 652.

42 CANTIMORI. Delio. Recensione di Vincenzo Cuoco. Il pensiero politico. A cura di G. Tarroni. Istituto Nazionale Fascista di Cultura. Cappelli, Bologna s.d. 1936. Leonardo, X, 1939. p. 17-19. In: Politica e storia contemporanea. Torino: Einaudi, 1991. p. 652. p. 652. Cf. AGUZZI, Luciano. Utopisti e Riformatori sociali nell'opera di Delio Cantimori (1937-1943). P. 5-58. In: Rivista Trimestre, s.d. 1989. p. 37. 
Ainda em 1939, Cantimori resenhou outra coleção de escritos políticos de Mario Pagano, ${ }^{43}$ na qual apresentou uma crítica ao organizador F. Collotti, por não tratar o caráter iluminista do pensamento de Pagano, ressaltando o temor ao iluminismo "como uma espécie de pecado" que proibia grandes homens, como V. Cuoco e M. Pagano, serem considerados iluministas. ${ }^{44}$

Perante tal posição, o estudioso italiano afirmou que o interesse histórico não consistiria em enxergar esses grandes homens como guias das nossas vidas, mas, sim, como magistri vitae da vida histórica da mente humana. Caso contrário, correr-se-ia o risco de retirar todos os pensadores dessa corrente de pensamento, sobrando, apenas, um conjunto de motivos abstratos que levariam à recorrente confusão de significados dos termos iluminismo e voltairismo. ${ }^{45}$

O ano letivo 1941-42 foi significativo para a apresentação da temática e a conclusão de suas pesquisas que culminariam na redação de seu livro sobre os reformadores políticos italianos. Naquele contexto, Cantimori direcionou um pouco mais da metade de seu curso na Scuola Normale para o debate sobre o "Socialismo utópico de Babeuf a 1848", apresentando aulas que abarcaram as ideias de Babeuf e o seu "babouvismo", o pensamento de Saint Simon e a escola sansimoniana, o princípio de associação em Mazzini e no sansimonismo, Fourier e a situação geral da sociedade entre 1796 e 1830, os alemães em Paris (1830-1840), Weitling, Lorenz von Stein (18151890), concluindo com o problema social e de unidade da Alemanha até $1848 .^{46}$

43 Francesco Mario Pagano (1748-1799) foi jurista, filósofo e político italiano, considerado um dos expoentes do iluminismo e precursor do positivismo, sendo um dos principais participantes da Fundação de República Napolitana. Essa república teve ajuda das tropas jacobinas francesas, mas foi, logo depois, eliminada pelo governo Bourbon, que dominava a região, antes das invasões.

44 CANTIMORI, Delio. Recensione di Mario Pagano, Saggi politici, a cura di F. Collotti, Istituto Nazionale Fascista di Cultura, Roma 1938. Leonardo, X, 1939. In: Politica e storia contemporanea. Torino: Einaudi, 1991. p. 656 e 657.

45 CANTIMORI, Delio. Recensione di Mario Pagano, Saggi politici, a cura di F. Collotti, Istituto Nazionale Fascista di Cultura, Roma 1938. Leonardo, X, 1939. In: Politica e storia contemporanea. Torino: Einaudi, 1991. p. 656 e 657. p. 657. Cf. AGUZZI, Luciano. Utopisti e Riformatori sociali nell'opera di Delio Cantimori (1937-1943). p. 5-58. In: Rivista Trimestre, s.d. 1989.p. 37 e 38.

46 Cf. MICCOLI, Giovanni. Delio Cantimori. La ricerca di una nuova critica storiografica. Torino: Giulio Einaudi editore, 1970. p. 341. AGUZZI, Luciano. Utopisti e Riformatori sociali nell'opera di Delio Cantimori (1937-1943). p. 5-58. In: Rivista Trimestre, s.d. 1989.p. 38. 


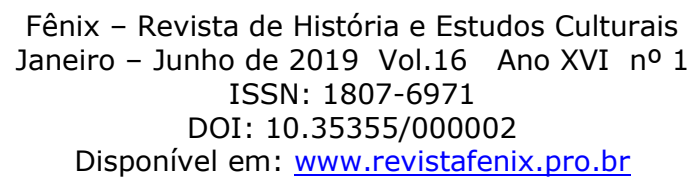

Provavelmente, utilizando parte dos materiais apresentados no curso, nesses anos, Cantimori também publicou, na revista Popoli, dois artigos intitulados Utopisti e riformatori sociali, sobre as trajetórias de Gracco Babeuf e Saint Simon.

Segundo Aguzzi, no primeiro artigo, o intelectual teria traçado o perfil de Babeuf, considerando-o o último defensor da ressurreição do jacobinismo de Robespierre. Dessa maneira, enfatizou seu projeto de reforma pedagógica da sociedade com base comunista e a tendência prática do seu pensamento, na tentativa de agir pela implantação de uma organização social igualitária, pela exaltação do trabalho manual e da força física, que teriam influenciado novas tentativas socialistas e comunistas nas décadas sucessivas, chegando ao reformador italiano Buonarroti.

Cantimori ainda definiu a sua concepção política como classicista, embasada na ideia de revolução, como uma guerra "santa e venerável" entre patrícios e plebeus, pobres e ricos, cujo sistema de comunismo agrário levava em consideração a indústria e o comércio, mas revelava-se utópico, ao considerar o exército como modelo para uma nova sociedade. ${ }^{47}$

Sobre Saint Simon, Cantimori não apresentara a mesma simpatia que possuía em relação aos preceitos políticos de Babeuf. Através da apresentação de uma bibliografia do "socialista utópico", o intelectual examinou seu pensamento, ressaltando as novas ideias sansimonianas, suas indeterminações e utopismos, que o levariam a se aproximar de intelectuais, técnicos e industriais, para sanar problemas das classes mais pobres. Para o estudioso italiano, Saint Simon posicionou-se como um precursor vago, que teria dado base para o socialismo e o industrialismo americano, para o Império liberal de Napoleão III, para a tecnocracia, o fordismo e outras espécies de solidariedade e produção, como fim das atividades humanas. ${ }^{48}$

Ainda em 1942, com o artigo sobre Vincenzio Russo, il Circolo costituzionale di Roma nel 1798 e la questione della toleranza religiosa, Cantimori passou da divulgação do trabalho ao tratamento mais científico do assunto, trabalhando o triênio revolucionário de 1796 e 1799.

\footnotetext{
47 AGUZZI, Luciano. Utopisti e Riformatori sociali nell'opera di Delio Cantimori (1937-1943). p. 558. In: Rivista Trimestre, s.d. 1989. p. 40.

48 Ibid., p. 41.
} 
Entre leituras de documentos, publicações raras, memórias do período e, sobretudo, da biografia já existente, Cantimori recebeu uma forte inspiração do livro Pensamenti politici do patriota italiano V. Russo, que impulsionou Cantimori na realização de pesquisas mais aprofundadas em relação à ideia de tolerância religiosa, que o pesquisador italiano colocava como um dos pontos de ligação mais importantes entre o pensamento moderno herético do Cinquecento e a religiosidade política do Settecento italiano.

A partir desse escrito, Cantimori conseguiu identificar a presença do ideal de igualdade anabatista - entendida pelo romagnolo como a verdadeira tolerância - no radicalismo de Russo, acompanhado pela defesa da liberdade política. Na interpretação de Cantimori, o pensamento de V. Russo levava os elementos basilares para a reforma religiosa, moral e política, o que despertou a atenção do estudioso romagnolo para a particularidade do jacobinismo desse patriota italiano. ${ }^{49}$

Ainda em 1942, Cantimori colaborou com a editora Einaudi, organizando uma antologia dos Discorsi parlamentari del Cavour, na qual foi autor do ensaio introdutório aos escritos políticos do estadista piemontês. Neste, direcionou sua atenção para a vida política e a importância do realismo político de Cavour para o Risorgimento laico italiano, contraposto ao neoguelfismo. ${ }^{50}$

Seus textos foram selecionados com base no interesse pela política interna e pelos conflitos do estadista com a extrema direita, os democráticos e com Giuseppe Mazzini. Dessa maneira, foi o Conde Cavour, "administrador, homem de governo e de partido", político criativo e dotado de ideias e princípios pragmáticos, quem o levou a concretizar o programa revolucionário de unificação nacional da Itália, como representante liberal, em meio aos conflitos contra conservadores, democráticos e mazzinianos. ${ }^{51}$

\footnotetext{
49 AGUZZI, Luciano. Utopisti e Riformatori sociali nell'opera di Delio Cantimori (1937-1943). p. 558. In: Rivista Trimestre, s.d. 1989. p. 42.

50 Ibid., p. 43.

51 Ibid., p. 43 e 44.
} 
No curso de 1942-43, Cantimori direcionou parte do conteúdo para "o abade Tocci e a sua família dos cristãos iguais", 52 do qual surgiu o capítulo inicial do seu livro Utopisti e Riformatori Italiani 1794-1847. Ricerche storiche, publicado em 1943.

Em sua introdução, significativamente intitulada Utopismo politico, sociale, religioso, Cantimori, referindo-se ao Saggio sulla Rivoluzione, de Carlo Pisacane ${ }^{53}$, ressaltou duas questões de vital importância para sua obra: o caráter precursor de suas ações dos reformadores italianos e a negligência da historiografia em relação às suas reformas sociais.

Segundo Cantimori, Pisacane teria colocado os reformadores italianos no mesmo patamar de Proudhon e os socialistas europeus, alinhando os italianos, que, como precursores, "compraram com sangue o direito à razão" 54 , à tradição do pensamento renascentista italiano.

Crítico dos filósofos do século XVIII, por ter conservado o ideal naturalista e ascético rousseauniano na formação das suas utopias comunistas, Pisacane atribuiu uma função especial aos italianos, ao vê-los como "a manifestação da razão coletiva, da dor constrita ao exame dos males sociais" e por terem apresentado o problema político sobre o plano social, ou seja, no verdadeiro local onde se pode estabelecer a ação revolucionária italiana e europeia, através dos estudos das leis que regulam a sociedade.

Com sua insistência em retornar aos patriotas italianos do Settecento, entendidos como apoiadores da reforma social voltada para a crítica do instituto da propriedade privada, segundo Cantimori, Pisacane teria apontado os pontos que foram negligenciados pela historiografia, de modo geral, preocupada com o estudo do momento político, em si.

A partir disso, Cantimori propôs uma investigação particular dos programas, utopias e projetos político-sociais de tendência socialista e comunista da metade do

52 MICCOLI, Giovanni. Delio Cantimori. La ricerca di una nuova critica storiografica. Torino: Giulio Einaudi editore, 1970. p. 341.

53 Carlo Pisacane (1818-1857) foi um patriota e revolucionário italiano, de ideologia socialista. Participou da Guerra de Independência de 1848, da formação da República Romana (1949), junto com G. Mazzini e G. Garibaldi. Com o objetivo de sublevar o Sul contra o monarca, Pisacane organizou, com Mazzini, uma expedição para Sarpi, quando seu grupo foi atacado por soldados bourbonicos e Pisacane foi morto.

54 CANTIMORI, Delio. Utopisti e Riformadori italiani (1794-1847). Ricerche storiche. Firenze: Sansoni, 1943.p. 9. 
Settecento, até das manifestações ocorridas na Itália, antes de 1848, levando em consideração a difusão das doutrinas elaboradas na França e difundidas na Itália. ${ }^{55}$

Permeando tudo isso, Cantimori chama a atenção para a profunda crença religiosa que perpassava a fé política desses reformadores, na luta pela renovação do ser humano e pela possibilidade de uma educação integral do homem para o bem, onde não se pudesse negligenciar sua relação histórica com os hereges e a defesa da tolerância na Reforma e Contrarreforma. ${ }^{56}$

Dessa maneira, Cantimori apresentaria seu principal trabalho sobre o novo filão historiográfico, que atravessou, também, os anos 50, sempre movido pelos interesses relacionados ao marxismo e à renovação interpretativa da historiografia italiana. Nesses escritos, também se entrelaçavam as utopias e os ideais igualitários, nos quais os reformadores e patriotas italianos se basearam para a criação de uma sociedade ética e moralmente elevada e que deixara como herança suas ideias não concretizadas, das quais, possivelmente, poderiam agora ser reerguidas pelo projeto político marxista italiano, em que Cantimori, então, depositava suas esperanças de renovação.

\section{CONCLỮ̃̃o}

No que se refere à formação ético-política italiana como problemática de interpretação histórica, Delio Cantimori carregou problemas originados em gerações de pensadores italianos de séculos precedentes que ajudaram a compor o corpo teórico das suas leituras do Idealismo Atualista.

O jovem romagnolo cresceu carregando questões tradicionalmente italianas, relacionadas à unificação da Itália, e permaneceu ocupado com a consolidação do Estado italiano e com a formação ético-moral do povo, quando se projetava como um homem de cultura.

Ao inserir-se na reflexão sobre essas temáticas, Delio Cantimori levou consigo forte influência dos ideais mazzinianos e do idealismo atualista, pensamento no qual organizou sua crença na Revolução Fascista como a grande responsável pela formação

\footnotetext{
55 Ibid., p. 11.

56 Ibid., p. 17-19.
} 
ético-moral do povo italiano, não cumprida integralmente pelos movimentos nacionais do Renascimento e do Risorgimento italiano.

Não obstante, a Concordata arruinou suas esperanças na sacralidade não confessional do fascismo e da filosofia idealista, fazendo com que Cantimori se aproximasse das correntes mais heterodoxas, ainda que atualistas, mas antiburguesas, de inspiração esquerdista, inclinadas à defesa do Estado Ético Corporativo como alternativa para superar o liberalismo e o comunismo soviético. ${ }^{57}$

Contudo, durante suas viagens em busca das pistas deixadas pelos hereges italiano do Cinquecento, Cantimori despertava sua consciência crítica para o universo político hostil que pairava nos ares europeus. Seu conhecimento histórico-filológico se tornava a arma cantimoriana de combate a qualquer tipo de apelo ao irracionalismo, como via de consolidação de um Estado ou Nação.

Nessas condições, o Estado cantimoriano tomava uma conotação de instituição necessariamente racional e ordenadora dos instintos, em contraposição ao nazismo e ao governo de Mussolini, que se aliaram no projeto expansionista e racista, em detrimento dos ideais corporativistas.

Estava selada a primeira desilusão política de Delio Cantimori, que começava a exercer oposição ao regime fascista, apoiando agentes ilegais do PCI e lançando críticas veladas ao modelo de sociedade defendido pelos fascistas, através de seus estudos sobre os reformadores, utopistas e jacobinos italianos do final do Settecento e da primeira metade do Ottocento.

Ao aproximar-se do PCI e do materialismo histórico, Cantimori não mais se atrevia a escrever textos intrinsecamente político-apologéticos, como fazia na sua juventude fascista.

Assim como acreditara no fascismo, agora o marxismo despontava como a ideologia capaz de promover a tão esperava renovação cultural italiana e europeia, de modo geral, tendo poder de combater a interferência da Igreja no Estado italiano e de promover uma verdadeira reforma dos valores ético-morais da sociedade.

Porém, com o passar dos anos, a ambição cantimoriana de formação do povo através do conhecimento crítico, adverso a qualquer interferência ideológica político-

57 CHIANTERA-STUTTE, Patricia. Delio Cantimori: un intellettuale del novecento. Roma: Carocci, 2011. p 21. 


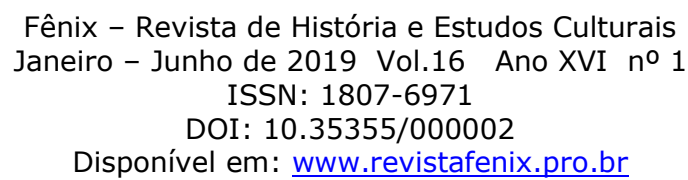

propagandista, entraria em colisão com as políticas culturais e os posicionamentos de alguns dos líderes e jovens intelectuais inseridos nos órgãos de cultura do PCI.

Sua irritação com o PCI misturava-se ao ambiente político europeu conturbado pelas notícias das barbaridades cometidas pelo governo de Stalin e a Revolta da Hungria, eventos desconfortantes que geraram uma forte crise na relação entre os intelectuais e o PCI.

Paulatinamente, o materialismo histórico e o PCI perdiam a áurea civilizadora para o intelectual romagnolo, que começava a sofrer novamente uma desorientação em relação ao desenrolar histórico. Naquele contexto, Cantimori chegou à convicção de ser incapaz de tecer uma compreensão do seu universo político contemporâneo, que esfacelava suas crenças ideológicas novamente. Agora, o romagnolo era tomado, novamente, pelo remorso em relação às suas escolhas políticas que o acompanhou até o findar dos seus dias. ${ }^{58}$

\section{RECEBIDO EM: 04/12/2017 。 PARECER DADO EM: 19/02/2018}

58 MANGONI, Luisa. L'Europa sotterranea. p. XIII-XLII. In: CANTIMORI, Delio. Politica e storia contemporanea. Torino: Einaudi, 1991. p. XLI. VITTORIA, Albertina. La "ricerca oggettiva": il rapporto fra la politica e la cultura per Gastone Manacorda e Delio Cantimori. Introduzione al carteggio. p. 9-136. In: Delio Cantimori, Gastone Manacorda. Amici per la storia - Lettere 19421966. Roma: Carocci editore, 2013. p. 73. 
Fênix - Revista de História e Estudos Culturais

Janeiro - Junho de 2019 Vol.16 Ano XVI no 1

ISSN: $1807-6971$

DOI: $10.35355 / 000002$

Disponível em: www.revistafenix.pro.br 